\title{
PERBEDAAN SEDIMEN URINE MASYARAKAT \\ BERDASARKAN JENIS KONSUMSI AIR MINUM
}

\section{DIFFERENCES IN COMMUNITY URINE SEDIMENT BY TYPE OF DRINKING WATER CONSUMPTION}

\author{
Hartini $^{1^{*}}$, Cristina Sigiro ${ }^{2}$, Dian $\mathrm{Ayu}^{3}$ \\ ${ }^{\mathbf{1 , 2 , 3}}$ Akademi Kesehatan John Paul II Pekanbaru, Jl.Permata I No.32, Pekanbaru, \\ 28292, Indonesia \\ *Surel : hartini.tini214@gmail.com
}

\begin{abstract}
Abstrak
Air merupakan kebutuhan yang paling penting bagi setiap makhluk hidup. Air minum yang aman bagi kesehatan adalah yang memenuhi persyaratan fisika, mikrobiologis, kimiawi, dan radioaktif. Kebutuhan akan air minum yang layak semakin meningkat seiring dengan cepatnya pertumbuhan jumlah penduduk, sehingga masyarakat terdorong untuk mencari alternatif lain yaitu dengan beberapa jenis air minum di antaranya air minum isi ulang dan air tanah artesis. Penelitian ini bertujuan untuk mengetahui gambaran sedimen urine pada masyarakat yang mengonsumsi air minum isi ulang dan air tanah artesis di Kecamatan Payung Sekaki Kota Pekanbaru. Jenis penelitian yang digunakan adalah deskriptif. Jumlah sampel sebanyak 32 yang terdiri dari 16 sampel urine masyarakat yang mengonsumsi air minum isi ulang dan 16 sampel urine dari masyarakat yang mengonsumsi air tanah artesis. Berdasarkan penelitian ditemukan hasil sedimen urine masyarakat yang mengonsumsi air minum isi ulang yaitu leukosit abnormal ditemukan pada 1 orang, epitel abnormal pada 6 orang. Sedangkan, sedimen urine masyarakat yang mengonsumsi air tanah artesis yaitu epitel abnormal ditemukan pada 2 orang.
\end{abstract}

Kata kunci : air minum, artesis, sedimen urine, masyarakat

\section{Abstract}

Water is the most important requirement for every living thing. Proper drinking water is one that meets the physical, microbiological, chemical and radioactive requirements. The need for proper drinking water is increasing along with the rapid population growth, so that people are encouraged to look for other alternatives, namely by several types of drinking water including refill drinking water and artesian ground water. This study aims to determine the description of urine sediment in people who consume refill drinking water and artesian ground water in the Payung Sekaki District, Pekanbaru. This type of research is descriptive. The total sample is 32 consisting of 16 urine samples of people who consume refill drinking water and 16 urine samples of people 
who consume artesian ground water. Based on research found that community urine sediment that consumes refill drinking water is abnormal leukocytes found in 1 person, abnormal epithelium in 6 people. Whereas community urine sediment that consumes artesian ground water which is abnormal epithelium was found in 2 people.

Keywords : drinking water, artesian, urine sediment, community

\section{Pendahuluan}

Air merupakan kebutuhan yang paling penting bagi setiap makhluk hidup. Menurut perhitungan World Health Organization (WHO) setiap orang di negara maju memerlukan air antara 60-120 L/hari sedangkan di negara berkembang termasuk Indonesia setiap orang memerlukan air antara 30$60 \mathrm{~L} /$ hari. Badan Internasional seperti United Nation for Children Funds (UNICEF) melaporkan bahwa kualitas air minum yang rendah dapat menjadi sumber berkembangnya beragam penyakit seperti diare, kolera dan gangguan pencernaan lainnya. (1) Menurut laporan UNICEF secara global, rendahnya kualitas air minum telah menyebabkan peningkatan probabilitas meninggalnya bayi usia dibawah 5 tahun hampir 1,3 juta jiwa per tahun. (2)

Kebutuhan akan air minum yang layak merupakan salah satu masalah dasar di Indonesia. Pada level kabupaten, rata-rata dari persentase penduduk dengan akses air bersih baru mencapai $49 \%$ dengan rentang distribusi antara $1 \%$ sampai dengan 100\%. (3) Menurut Permenkes Nomor 92/Menkes/Per/IV/2010 tentang persyaratan kualitas air minum menyatakan bahwa air minum yang aman bagi kesehatan adalah yang memenuhi persyaratan fisika, mikrobiologis, kimiawi dan radioaktif yang dimuat dalam parameter wajib dan tambahan. $(4,5)$

Air minum terus-menerus dibutuhkan masyarakat seiring dengan cepatnya pertumbuhan jumlah penduduk, sehingga masyarakat terdorong untuk mencari alternatif lain yaitu dengan beberapa jenis air minum, salah satunya air minum isi ulang. Air minum isi ulang banyak dikonsumsi karena harganya yang murah dan siap untuk dikonsumsi. (6) Air tanah artesis juga menjadi salah satu kebutuhan air minum pada saat musim kemarau. Namun air tanah artesis biasanya mengandung bahan logam berat besi (Fe) dan mangan (Mn). (7) Penggunaan air minum yang tidak memenuhi syarat kesehatan dapat menyebabkan penyakit 
dan gangguan fungsi organ tubuh seperti fungsi ginjal, hati, otak dan beberapa zat kristal juga dapat ditemukan pada urine yang bersifat abnormal terhadap tubuh manusia seperti kalsium oksalat, triple fosfaf, silinder dan sebagainya. Pemeriksaan sedimen urine adalah salah satu pemeriksaan rutin, yaitu suatu jenis pemeriksaan yang menggunakan metode mikroskopis. (6)

Penelitian ini bertujuan untuk mengetahui distribusi sedimen urine berdasarkan jenis kelamin dan kelompok usia pada masyarakat yang mengonsumsi air minum isi ulang dan air tanah artesis.

\section{Metode}

Metode yang digunakan pada penelitian ini adalah deskriptif. Penelitian dilakukan di Akademi Kesehatan John Paul II Pekanbaru pada rentang waktu Juni 2018-September 2019.

Bahan yang digunakan pada penelitian yaitu pot urine, objek glass, cover glass, tabung reaksi, mikroskop binokuler merek Olympus tipe 22, pipet tetes, centrifuge merek Nesco. Alat yang digunakan pada penelitian yaitu air minum isi ulang dan air tanah artesis.
Populasi penelitian adalah masyarakat yang berdomisili di Kecamatan Payung Sekaki Kota Pekanbaru. Sampel penelitian yaitu urine pagi dari masyarakat Kecamatan Payung Sekaki Kota Pekanbaru dengan total sampel adalah 32 sampel urine pagi yang terdiri dari 16 sampel urine masyarakat yang mengonsumsi air minum isi ulang dan 16 sampel urine pagi masyarakat yang mengonsumsi air tanah artesis.

Prosedur kerja penelitian antara lain urine yang diambil sebagai sampel adalah urine midstream yang pertama kali keluar pada pagi hari dan dikumpulkan dengan menggunakan wadah tampungan khusus urine sebanyak 20-30 mL; sedimen urine dihomogenkan; diambil 7-8 $\mathrm{mL}$ urine homogen ke dalam tabung reaksi; disentrifuga selama 5 menit dengan kecepatan 1500-2000 rpm; supernatan dibuang hingga volume sedimen tersisa 0,5-1 $\mathrm{mL} ;$ sedimen urine tersebut diteteskan sebanyak 2 tetes di atas objek glass dan ditutup dengan cover glass; diamati menggunakan mikroskop minimal 10 lapang pandang dengan perbesaran $100 \times$ dan $400 \times$. 
Hasil minum isi ulang dan air tanah artesis di Berdasarkan data sampel Kecamatan Payung Sekaki Kota penelitian sebanyak 32 orang, diperoleh Pekanbaru.

hasil pemeriksaan sedimen urine pada masyarakat yang mengonsumsi air

Tabel 1.

Distribusi Sampel Berdasarkan Jenis Kelamin Dan Kelompok Usia

\begin{tabular}{lcccc}
\hline \multirow{2}{*}{ Distribusi sampel } & \multicolumn{2}{c}{ Air Minum Isi Ulang } & \multicolumn{2}{c}{ Air Tanah Artesis } \\
\cline { 2 - 5 } & Jumlah (N) & $\%$ & Jumlah (N) & $\%$ \\
\hline Jenis kelamin & 3 & 18,8 & & \\
Laki-laki & 13 & 81,2 & & \\
Perempuan & & & & \\
Kelompok usia (tahun) & & 6,25 & 3 & 18,75 \\
$6-12$ & 2 & 37,5 & 3 & 18,75 \\
$13-19$ & 10 & 62,5 & 3 & 18,75 \\
$20-26$ & 2 & 12,5 & 1 & 6,25 \\
$27-32$ & 1 & 6,25 & 2 & 12,5 \\
$33-39$ & 0 & 0 & 3 & 18,75 \\
$40-46$ & 0 & 0 & 1 & 6,25 \\
$47-53$ & 16 & 100 & 16 & 100 \\
Total & & & &
\end{tabular}

Tabel 1 menunjukkan kelompok usia 20-26 tahun adalah masyarakat yang mengonsumsi air minum isi ulang paling banyak dengan persentase 62,5 $\%$, sedangkan kelompok usia 40-46 dan 47-53 tidak ada yang mengonsumsi AMIU. Berdasarkan kelompok usia, masyarakat yang mengonsumsi air tanah artesis terdapat pada kelompok usia 6-12 tahun, 13-19 tahun, 20-26 tahun, dan 40-46 tahun adalah usia yang memiliki persentase tertinggi di kelompoknya dengan persentase masing-masing sebesar $18,75 \%$.

Sampel urine pagi masyarakat yang mengonsumsi AMIU secara keseluruhan memiliki jumlah eritrosit dan kalsium oksalat yang normal. Sedangkan jumlah leukosit, epitel dan bakteri ditemukan dalam kondisi abnormal. Jumlah epitel normal dibanding abnormalnya lebih rendah, yaitu 2 sampel urine (25\%) normal berbanding dengan 6 sampel $(75 \%)$ abnormal. Persentase jumlah leukosit yang normal $87,5 \%$, persentase jumlah leukosit yang abnormal 12,5\%. Persentase jumlah bakteri yang normal $62,5 \%$, persentase jumlah bakteri yang abnormal 37,5\%. Sampel urine sewaktu masyarakat yang mengonsumsi AMIU secara keseluruhan memiliki jumlah 
eritrosit, leukosit dan kalsium oksalat yang normal. Sedangkan jumlah epitel dan bakteri ada ditemukan dalam kondisi abnormal. Persentase jumlah epitel yang normal $37,5 \%$, persentase jumlah epitel yang abnormal $62,5 \%$. Persentase jumlah bakteri yang normal $75 \%$, persentase jumlah bakteri yang abnormal 25\% (Tabel 2).

Tabel 2.

\section{Sedimen Urine Pada Masyarakat Yang Mengonsumsi Air Minum Isi Ulang}

\begin{tabular}{|c|c|c|c|c|c|c|c|c|}
\hline \multirow{3}{*}{$\begin{array}{l}\text { Sedimen } \\
\text { Urine }\end{array}$} & \multicolumn{4}{|c|}{ Urine Pagi } & \multicolumn{4}{|c|}{ Urine Sewaktu } \\
\hline & \multicolumn{2}{|c|}{ Normal } & \multicolumn{2}{|c|}{ Abnormal } & \multicolumn{2}{|c|}{ Normal } & \multicolumn{2}{|c|}{ Abnormal } \\
\hline & $\mathrm{N}$ & $\%$ & $\mathrm{~N}$ & $\%$ & $\mathrm{~N}$ & $\%$ & $\mathrm{~N}$ & $\%$ \\
\hline Eritrosit & 8 & 100 & 0 & 0 & 8 & 100 & 0 & 0 \\
\hline Leukosit & 7 & 87,5 & 1 & 12,5 & 8 & 100 & 0 & 0 \\
\hline Epitel & 2 & 25 & 6 & 75 & 3 & 37,5 & 5 & 62,5 \\
\hline Kalsium Oksalat & 8 & 100 & 0 & 0 & 8 & 100 & 0 & 0 \\
\hline Bakteri & 5 & 62,5 & 3 & 37,5 & 6 & 75 & 2 & 25 \\
\hline
\end{tabular}

Sampel urine pagi dan sewaktu pada masyarakat yang mengonsumsi air tanah artesis seluruhnya memiliki jumlah eritrosit, leukosit, kalsium oksalat dan bakteri yang normal. Sedangkan pada pemeriksaan terhadap jumlah epitel ditemukan 6 sampel urine pagi $(75 \%)$ dan 5 sampel urine sewaktu $(62,5 \%)$ dengan jumlah epitel yang normal, 2 sampel urine pagi (25\%) dan $3(37,5 \%)$ sampel urine sewaktu dengan jumlah epitel yang abnormal (Tabel 3).

Tabel 3.

Sedimen Urine Pada Masyarakat Yang Mengonsumsi Air Tanah Artesis

\begin{tabular}{|c|c|c|c|c|c|c|c|c|}
\hline \multirow{3}{*}{$\begin{array}{l}\text { Sedimen } \\
\text { Urine }\end{array}$} & \multicolumn{4}{|c|}{ Urine Pagi } & \multicolumn{4}{|c|}{ Urine Sewaktu } \\
\hline & \multicolumn{2}{|c|}{ Normal } & \multicolumn{2}{|c|}{ Abnormal } & \multicolumn{2}{|c|}{ Normal } & \multicolumn{2}{|c|}{ Abnormal } \\
\hline & $\mathrm{N}$ & $\%$ & $\mathrm{~N}$ & $\%$ & $\mathrm{~N}$ & $\%$ & $\mathrm{~N}$ & $\%$ \\
\hline Eritrosit & 8 & 100 & 0 & 0 & 8 & 100 & 0 & 0 \\
\hline Leukosit & 8 & 100 & 0 & 0 & 8 & 100 & 0 & 0 \\
\hline Epitel & 6 & 75 & 2 & 25 & 5 & 62,5 & 3 & 37,5 \\
\hline Kalsium Oksalat & 8 & 100 & 0 & 0 & 8 & 100 & 0 & 0 \\
\hline Bakteri & 8 & 100 & 0 & 0 & 8 & 100 & 2 & 25 \\
\hline
\end{tabular}

\section{Pembahasan}

Penelitian ini menggunakan sampel urine masyarakat yang berdomisili di Kecamatan Payung
Sekaki Kota Pekanbaru. Sebanyak 32 sampel urine dikelompokkan berdasarkan jenis air yang dikonsumsi yaitu air minum isi ulang dan air tanah artesis. Sedimen urine yang diperiksa 
meliputi eritrosit, leukosit, epitel, kalsium oksalat dan bakteri.

Berdasarkan

pemeriksaan

sedimen urine masyarakat yang mengonsumsi air minum isi ulang dan air tanah artesis di Kecamatan Payung Sekaki Kota Pekanbaru terdapat variasi gambaran sedimen. Menurut Kementerian Kesehatan Republik Indonesia dalam pedoman interpretasi data klinik tahun 2011 bahwa eritrosit yang normal pada sedimen urine yaitu 0-3 sel/LPB. Leukosit yang normal pada sedimen urine yaitu $0-5$ sel/LPB. Epitel yang normal pada sedimen urine yaitu 0-2 sel/LPB. Kalsium oksalat dan Bakteri yang normal yaitu negatif (tidak ditemukan pada sedimen urine. (8)

Distribusi sampel penelitian berdasarkan jenis kelamin ditampilkan dalam Tabel 1 menunjukkan bahwa perempuan lebih banyak mengonsumsi air minum isi ulang dan air tanah artesis dibandingkan laki-laki, karena berdasarkan hasil kuesioner yang bersedia untuk dijadikan sampel adalah mayoritas perempuan. Responden yang dijadikan sebagai subjek penelitian memiliki usia 6 hingga 53 tahun, yang selanjutnya dibagi menjadi 7 kelompok usia. Kelompok usia 20-26 tahun $(62,5 \%)$ lebih banyak mengonsumsi
AMIU, sedangkan masyarakat yang mengonsumsi air tanah artesis terbanyak pada kelompok usia 6-12 tahun, 13-19 tahun, 20-26 tahun dan 4046 tahun dengan persentase $18,75 \%$.

Sampel urine pagi dan sewaktu masyarakat yang mengonsumsi air minum isi ulang dan air tanah artesis tidak ditemukan sel eritrosit yang artinya seluruh sampel urine tidak ada yang mengandung eritrosit. Berdasarkan hasil kuesioner, secara keseluruhan masyarakat tidak memiliki riwayat penyakit atau kelainan ginjal. Jika jumlah eritrosit lebih dari normal dapat menggambarkan adanya trauma atau perdarahan pada ginjal dan saluran kemih. (9) Eritrosit yang terdapat dalam urine berbentuk bulat tanpa struktur mempunyai warna kehijau-hijauan. (10)

Hasil pemeriksaan sedimen urine masyarakat yang mengonsumsi AMIU ditemukan 1 sampel urine pagi $(6,25 \%)$ memiliki jumlah leukosit yang abnormal, 7 sampel urine pagi $(87,5 \%)$ dan 8 sampel urine sewaktu (100\%) memiliki jumlah leukosit yang normal. Leukosit dalam urine berbentuk bulat dan didalamnya terdapat butiran halus. (10) Menurut Purwaningsih dan Widyastuti, terdapatnya leukosit dalam urine merupakan salah satu tanda 
adanya peradangan pada saluran kemih. (11) Sebagai tambahan, hasil kuesioner secara keseluruhan tidak ditemukan adanya riwayat penyakit. Hal ini dapat terjadi karena masyarakat tidak melakukan pemeriksaan secara berkala sehingga tidak mengetahui adanya riwayat penyakit yang dimiliki.

Kristal kalsium oksalat juga tidak ditemukan pada pemeriksaan sedimen urine karena berdasarkan hasil kuesioner seluruh masyarakat tidak memiliki riwayat penyakit diabetes dan penyakit asam urat. Kalsium oksalat merupakan kristal yang paling sering ditemukan pada urine asam serta memiliki bentuk yang bervariasi. Bentuk yang umum adalah bentuk dihidrat, kristal berwarna mirip bentuk amplop. (5) Menurut Yunus dan Yuniarty, adanya kristal dalam urine dapat mengindikasikan adanya gangguan pada fungsi ginjal. (6) Selain itu, terbentuknya kristal dalam urine juga menunjukkan adanya predisposisi, yang sering disebut dengan kencing batu. Kesadahan air minum tidak ada hubungan dengan terbentuknya kristal kalsium oksalat dalam urine, tetapi terbentuknya kristal kalsium oksalat dalam urine dipengaruhi oleh konsumsi makanan yang mengandung kalsium, fosfor, asam sitrat, dan asam urat serta kebiasaan minum kurang dari 1,5 liter/hari.

Hasil pemeriksaan sedimen urine masyarakat yang mengonsumsi air minum isi ulang ditemukan 6 sampel urine pagi (75\%) dan 5 sampel urine sewaktu $(62,5 \%)$ memiliki jumlah epitel yang abnormal, 2 sampel urine pagi $(25 \%)$ dan 3 sampel urine sewaktu $(37,5 \%)$ memiliki jumlah epitel normal. Sebaliknya, pada hasil pemeriksaan sedimen urine masyarakat yang mengonsumsi air tanah artesis ditemukan 2 sampel urine pagi (25\%) dan $3(37,5 \%)$ sampel urine sewaktu memiliki jumlah epitel yang abnormal, 6 sampel urine pagi (75\%) dan 5 sampel urine sewaktu $(62,5 \%)$ memiliki jumlah epitel yang normal. Menurut Gandosoebrata, sel epitel dalam urine dapat terjadi karena adanya iritasi atau peradangan pada tractus urogenitalis. (9) Epitel adalah sel yang berinti satu, ukurannya lebih besar dari leukosit, bentuknya berbeda menurut tempat asalnya. Sel epitel gepeng (skuamosa) lebih banyak terdapat pada urine wanita yang berasal dari vulva, sel epitel tubular renal bentuknya lebih bulat dan lebih kecil dari epitel skuamosa. Sel ini berasal dari pelvis ginjal dan tubulus 
ginjal sedangkan sel epitel transisional bentuknya memanjang dan mempunyai tonjolan. (10)

Hasil pemeriksaan sedimen urine masyarakat yang mengonsumsi air minum isi ulang ditemukan 3 sampel urine pagi $(37,5 \%)$ dan 2 sampel urine sewaktu (25\%) memiliki jumlah bakteri yang abnormal, 5 sampel urine pagi $(62,5 \%)$ dan 6 sampel urine sewaktu (75\%) memiliki jumlah bakteri yang normal. Bakteri yang terdapat dalam sedimen urine disebabkan oleh kontaminasi pada saat penampungan sampel urine. (5)

\section{Kesimpulan}

1. Sedimen urine masyarakat yang mengonsumsi air minum isi ulang mengandung jumlah leukosit yang abnormal pada 1 orang dan jumlah epitel yang abnormal juga ditemukan pada 6 orang berdasarkan sampel urine pagi.

2. Sedimen urine pada masyarakat yang mengonsumsi air tanah artesis ditemukan jumlah epitel yang abnormal pada 2 orang berdasarkan sampel urine pagi.

\section{Referensi}

1. Sukartini, N.M, \& Saleh. Akses Air Bersih di Indonesia. Ekonomi Kuantitatif Terapan. 2016; 2 (9): 8998.

2. UNICEF Indonesia. Ringkasan Kajian Air Bersih, Sanitasi, dan Kebersihan; 2012.

3. BPS. 2015

4. Peraturan Menteri Kesehatan Nomor 492/MENKES/PER/IV/2010 Tentang Persyaratan Kualitas Air Minum (Studi Terhadap Depot Air Minum Isi Ulang di Wilayah Kelurahan Sekaran Gunung Pati Kota Semarang), Skripsi tidak diterbitkan. Semarang : Fakultas Hukum, Universitas Negeri Semarang.

5. Mongan, R., Supiati., Mangiri. Gambaran Sedimen Urine Pada Masyarakat yang Mengkonsumsi Air Pegunungan di Kecamatan Kendari Barat Kota Kendari. Teknologi Laboratorium. 2017; 1 (6): 18-24.

6. Yunus, R., \& Yuniarty, T. Gambaran Hasil Pemeriksaan Kristal Urin dari Orang yang Meminum Air Minum Kemasan Isi Ulang (Air Galon) dan Orang yang Meminum Air Minum dari Sumur Gali. Meditory. 2016; 1 
(4): 1-6.

7. Amri, H., \& Amri, S. Pengolahan Air Tanah Artesis Menjadi Air Layak Minum di Desa Buruk Bakul.

Di dalam: Seminar Nasional IIB Darmajaya Lembaga Penelitian, Pengembangan Pembelajaran dan Pengabdian kepada Masyarakat; Bengkalis, 25 Oktober 2017. Polikteknik Negeri, Bengkalis. 2017; 75-81.

8. Kementerian Kesehatan RI. Pedoman Interpretasi Data Klinik, Jakarta; 2011.

9. Gandosoebrata, R. Penuntun Laboratorium Klinik. Dian Rakyat, Jakarta; 2010.

10. Taurusita, D., Handayati, A., Hermawati, E., Sumarni, T. Kimia
Klinik Program Keahlian Teknologi Laboratorium Medik. Jakarta : Penerbit Buku Kedokteran; 2017.

11. Purwaningsih, N.V., \& Widyastuti, R. Perbandingan Pemeriksaan Leukosit Urine Segar dengan Setelah 2 Jam di Suhu Kamar. The Journal of Muhammadiyah Medical Laboratory Technologist, 2 (1): 1420. 